\title{
Perceptions of Manipulation and Judgments of Illegitimacy: Pitfalls in the Use of Emphasis Framing when Communicating about $\mathrm{CO}_{2}$ Capture and Storage
}

\section{Gerdien de Vries, Bart W. Terwel \& Naomi Ellemers}

To cite this article: Gerdien de Vries, Bart W. Terwel \& Naomi Ellemers (2016) Perceptions of Manipulation and Judgments of Illegitimacy: Pitfalls in the Use of Emphasis Framing when Communicating about $\mathrm{CO}_{2}$ Capture and Storage, Environmental Communication, 10:2, 206-226, DOI: $10.1080 / 17524032.2015 .1047884$

To link to this article: https://doi.org/10.1080/17524032.2015.1047884

View supplementary material $\widetilde{ }$

\section{Published online: 25 Jun 2015.}

Submit your article to this journal $\widetilde{T}$

Џll Article views: 288

View Crossmark data \lceil

Citing articles: 11 View citing articles $\sqsubset$ 


\title{
Perceptions of Manipulation and Judgments of Illegitimacy: Pitfalls in the Use of Emphasis Framing when Communicating about $\mathrm{CO}_{2}$ Capture and Storage
}

\author{
Gerdien de Vries, Bart W. Terwel \& Naomi Ellemers
}

The mitigation of climate change requires reductions in the amount of $\mathrm{CO}_{2}$ emitted into the atmosphere. One way to achieve this in the short run is through the implementation of $\mathrm{CO}_{2}$ capture and storage (CCS) technology. The viability of CCS not only depends on technical and regulatory issues, but also on public attitudes. Communication plays an important role in shaping these attitudes. This paper reports on two experiments performed to examine effects of emphasis framing in CCS communications, meaning that greater weight is given to advantages of CCS over disadvantages or vice versa. Although emphasis framing can be effective in shaping attitudes, our findings suggest that there may be long-term costs to using this communication technique as it can be perceived as manipulative. Moreover, emphasis framing is judged as relatively illegitimate when the source is expected to be impartial rather than biased.

Keywords: $\mathrm{CO}_{2}$ capture and storage (CCS); emphasis framing; legitimacy judgments; manipulation; climate change mitigation

\section{Introduction}

One of the greatest environmental challenges the world is facing today is combating global warming. According to the Intergovernmental Panel on Climate Change (IPCC), the warming of the climate system is unequivocal and has several harmful

\footnotetext{
This work was prepared while Gerdien de Vries (Ph.D.) was a Ph.D. student at the University of Leiden, the Netherlands. Bart Terwel (Ph.D.) is a Senior Researcher, and Naomi Ellemers (Ph.D.) is a Professor in the Department of Social and Organizational Psychology, Leiden University, the Netherlands. Email: g.devries-2@ tudelft.nl
} 
consequences, including the disturbance of ecosystems, the extinction of some plant and animal species, and rising sea levels (IPCC, 2013). Global warming is largely due to the growing emissions of the greenhouse gas carbon dioxide $\left(\mathrm{CO}_{2}\right)$. Emissions of $\mathrm{CO}_{2}$ partly result from natural-induced processes, but human-induced emissionsprimarily the $\mathrm{CO}_{2}$ released from the combustion of coal, oil, and natural gas during energy generation-are regarded as the most important contributors to global warming (IPCC, 2013; WMO, 2013). Therefore, many industrialized countries have agreed to reduce their emissions of $\mathrm{CO}_{2}$ and other greenhouse gases (UN, 1998, 2012). The implementation of $\mathrm{CO}_{2}$ capture and storage (CCS) technology can be helpful in this regard (IPCC, 2007).

In a nutshell, CCS involves the capture of $\mathrm{CO}_{2}$ in fossil fuel power plants or other major industrial processes, and the subsequent transport and long-term storage of this $\mathrm{CO}_{2}$ in deep geological formations such as depleted natural gas fields and saline aquifers. CCS can contribute significantly to meeting $\mathrm{CO}_{2}$ emission reduction targets, but the viability of CCS depends on several factors. These factors not only concern technical and regulatory issues that need to be dealt with, but also include the degree to which the public accepts CCS as a $\mathrm{CO}_{2}$ emission reduction measure. That is to say, a lack of public acceptance can be a serious impediment to the realization of CCS projects. For instance, plans for a CCS project in the Dutch town of Barendrecht were canceled in 2010 after it became evident that the vast majority of local residents were strongly against the proposed project (Terwel, Ter Mors, \& Daamen, 2012).

Research has shown that people's attitudes toward novel and complex technologies (such as CCS) are largely influenced by how the properties of these technologies are framed in stakeholder communications and in the media (e.g., Cobb, 2005; Druckman \& Bolsen, 2011; Jones, Eiser, \& Gamble, 2012). Indeed, a qualitative analysis of the Barendrecht CCS case indicates that the predominantly negative attitude toward CCS of local residents was not only the result of fear about safety and fall in property value, but also the result of framing (Brunsting, de Best-Waldhober, Feenstra, \& Mikunda, 2011). In their communications, project partners emphasized the societal benefits of the CCS project $\left(\mathrm{CO}_{2}\right.$ emission reduction) and paid much less attention to the potential costs. Residents referred to this positive framing as "proCCS propaganda" (Brunsting et al., 2011, p. 6379): an attempt to persuade them to support the project (i.e., manipulation). This created a climate of mistrust that paved the way for the local activist group "CO2isNee" (translated: CO2isNo) to intensify local opposition against the project through negatively framed publications on their website and in local newspapers (Brunsting et al., 2011; Terwel et al., 2012). Importantly, framing is not only applied in communications by proponents and opponents, but also in news articles that inform the public about CCS (Asayama \& Ishii, 2013; Feldpausch-Parker et al., 2013; Nerlich \& Jaspal, 2013). Because of the potential pitfalls in the use of framing when communicating about CCS (as shown by the Barendrecht case), we decided to take a closer look at framing effects in the context of CCS. 
In this paper, we present experimental research designed to show potential negative effects of framing. Our research complements previous research, which has primarily focused on the effectiveness of framing techniques in terms of their usefulness for influencing people's attitudes with respect to the issue at hand. We examine not only how framing in stakeholder communications and in news articles about CCS might affect people's attitudes toward the issue, but we also investigate the impact of framing on perceptions of manipulation and legitimacy judgments.

\section{Emphasis framing}

More often than not, communications that inform the public about novel technologies are persuasive in nature. Persuasive communication (through websites, leaflets, or other publications) can be a useful strategy for stakeholders that aim to create, reinforce, modify, or extinguish the beliefs, attitudes, intentions, motivations, and/or behaviors of their target audience (Fishbein \& Ajzen, 1975; Gass \& Seiter, 2007; Hovland, Janis, \& Kelley, 1953). A typical way to develop persuasive communications is by means of “emphasis framing” (Chong \& Druckman, 2007; Nelson, Clawson, \& Oxley, 1997). ${ }^{1}$

Emphasis framing is a communication technique that involves the presentation of information in ways that a particular position is advanced over another, often with the aim to nudge people into that position (e.g., Chong \& Druckman, 2007). This framing can be done strongly by reporting merely the positive aspects of CCS while ignoring any negative aspects (i.e., one-sided framing), or more subtly by covering both positive and negative aspects of CCS but with a greater emphasis on the positive aspects (i.e., two-sided framing). It is important to realize that framing is not "placing a false spin" on an issue, but may be used to convey accurate information while giving greater weight to a certain aspect over another (Nisbet, 2009).

Research has shown that emphasis framing can influence people's attitudes toward controversial issues. For example, Druckman and Bolsen (2011) observed that the positive one-sided message that genetically modified (GM) foods can help combat world hunger moved people into a more positive position on such foods than the negative one-sided message that GM foods impact on biodiversity and the food chain. Moreover, Nelson and colleagues (1997) found that people were more tolerant of a rally planned by the Ku Klux Klan after they had read a two-sided news article emphasizing the aspect of freedom of speech than after they had read an article emphasizing the risk to public safety.

\section{Perceived manipulation}

Emphasis framing-either one-sided or two-sided-might thus nudge people into a more positive or negative position on the implementation of CCS. At the same time, people who read a message that emphasizes a certain aspect of CCS over another may interpret the message as an attempt to persuade them into supporting a particular position. In fact, people are generally quite capable of distinguishing purely informative communications from communications that aim to persuade them into 
accepting a certain standpoint on the issue at hand (Campbell \& Kirmani, 2000; Friestad \& Wright, 1994). Therefore, we propose that although emphasis framing may be effective in shaping people's attitudes toward CCS, a potential pitfall in the use of this technique is that it can be perceived as manipulative. More specifically, we predict that people will perceive more manipulation when they read an article that emphasizes the advantages over the disadvantages of CCS (or vice versa), as compared to when they read a balanced article.

Furthermore, relevant to the issue of perceived manipulation is whether information about CCS comes from parties with an interest in CCS (e.g., an oil company) or from news agencies, which may be supposed to be unbiased. Recent studies show that people perceive and evaluate communications about environmental issues such as climate change and CCS differently depending on the communication source (Rabinovich, Morton, \& Birney, 2012; Ter Mors, Weenig, Ellemers, \& Daamen, 2010; Terwel, Harinck, Ellemers, \& Daamen, 2009a). Dual process models such as the Heuristic-Systematic Model (Chaiken, 1980) and the Elaboration Likelihood Model (Petty \& Cacioppo, 1986) are helpful to explain such source effects. According to these models, recipients process information in a more or less systematic (central) or heuristic (peripheral) way, with the judgments of people who process information heuristically being largely guided by such cues as the identity of the source.

Based on the notion that humans are "cognitive misers" who generally tend to afford as little cognitive effort as possible (Fiske \& Taylor, 1991), people are naturally inclined to process information rather heuristically. People are especially likely to follow a peripheral route of information processing when they are not very motivated or unable (e.g., due to time constraints or because the matter is too complex) to process information systematically (Chaiken, 1980; Petty \& Cacioppo, 1986). Considering that CCS is quite a complex issue, we propose that the identity of the source-in particular whether a source is assumed to be biased or unbiased in its reporting about CCS - is one heuristic cue that might play a role in how people perceive and react to communications targeted at them. More specifically, we predict that communications about CCS produced by an oil company with an interest in the implementation of CCS are more readily perceived as manipulative than communications produced by a news agency that can be assumed to be impartial.

\section{Legitimacy judgments}

The fact that people may perceive emphasis framing as manipulative not necessarily implies that emphasis framing is also judged as inappropriate. People are accustomed to the fact that organizations with a specific interest in an issue use persuasive communication techniques such as emphasis framing to try to gain the favors of the public (Campbell, 1995; Campbell \& Kirmani, 2000; Friestad \& Wright, 1994). Therefore, biased messages from oil companies pursuing the implementation of CCS are probably not considered less legitimate than balanced messages. Things may be different for news agencies though. These types of organizations may be blamed for producing biased coverage of CCS. That is to say, people expect news agencies to cover 
issues objectively as well as without bias (i.e., impartiality; Ryan, 2001). Balanced reporting is an important norm in this regard, although it should be noted that there are issues for which holds true that balanced reporting in itself paints an incorrect picture of the issue. After all, balanced reporting can make two opposing viewpoints look equally plausible, while one has the preponderance of evidence on its side. As such, concern with balance can in fact undermine true objectivity (Lichtenberg, 2000). This phenomenon is also referred to as "false balance" (Dearing, 1995). However, with regard to the complex issue of CCS, there are both important risks and benefits associated with the deployment of the technology. People may feel that the risks and benefits deserve equal attention in news coverage. Hence, we propose that an imbalance due to emphasis framing in news agencies' reporting of the advantages and disadvantages is considered less legitimate than balanced reporting of pros and cons. Along these lines, we also predict that the relationship between perceived manipulation and legitimacy judgments is stronger when people evaluate an article about CCS from news agencies than when they evaluate communications from oil companies.

\section{Overview of hypotheses}

In sum, we will test four hypotheses in this study:

Hypothesis 1: People perceive more manipulation when reading articles about CCS that emphasize advantages or disadvantages compared to when they read a balanced article.

Hypothesis 2: People perceive less manipulation in communications from news agencies than in communications from oil companies.

Hypothesis 3: People consider it less legitimate when news agencies supply biased rather than balanced information about CCS. This effect is not observed when information stems from oil companies.

Hypothesis 4: The relationship between perceived manipulation and judgments of illegitimacy is stronger when information about CCS stems from news agencies than when it stems from oil companies.

We test these four hypotheses in two experiments. Experiment 1 tests Hypothesis 1 using biased (one-sided and two-sided) and balanced news articles about CCS and explores whether or not emphasis framing can shape people's attitudes toward CCS. Experiment 2 tests all four hypotheses by looking at the combined effects of emphasis framing and communication source on perceived manipulation and legitimacy judgments. Specifically, Experiment 2 focuses on differences between (positively) biased and balanced information, either from a news agency or an oil company involved in CCS.

\section{Experiment 1}

\section{Method}

Participants and design. Participants were 120 undergraduate students from the Faculty of Social and Behavioral Sciences at Leiden University (20 male and 99 female 
[1 unspecified]; $M_{\text {age }}=19.83, S D=3.91$ ). Sixty-three participants had heard about CCS prior to participating in the experiment, while 57 participants had not. Awareness of CCS did not moderate the results reported here and will not be discussed any further. Participants were randomly allocated to either one of five experimental conditions (Communication: one-sided pro CCS vs. two-sided pro CCS vs. balanced vs. two-sided con CCS vs. one-sided con CCS). Participants received either $€ 1.50$ or course credits for their voluntary participation.

Procedure. The experiment consisted of two parts. First, participants were requested to indicate their gender and age, and to answer some general questions. ${ }^{2}$ Among these questions were items assessing how important participants considered a number of environmental topics to be. Two of these topics-combating global warming and the quality of groundwater-were of primary interest because these topics were addressed in our communication manipulation and we wanted to be able to confirm that they were judged as relevant. The remaining environmental topics were filler items concerning GM food, air pollution, and deforestation. After participants had completed this first part of the experiment, they were presented with a fictitious news article about CCS (see "Stimulus materials" section). When they had read the article, participants completed another questionnaire, which included items to measure attitudes toward CCS, perceived manipulation, awareness of CCS, and perceived emphasis of the article (i.e., the manipulation check). Finally, participants were debriefed, paid, and thanked for their participation.

Stimulus materials. We tailored the appearance of the article after true newspaper copy, following previous experimental research on emphasis framing (e.g., Druckman, 2001). The article was allegedly written by the Dutch national news agency ANP and displayed the logo of the agency in the upper left corner. In the opening paragraph, all articles provided the same general background information about $\mathrm{CO}_{2}$ and CCS. The differences between the articles were in the headline and following paragraphs. The one-sided articles addressed either the positive consequences of CCS for the climate (stating that CCS helps to combat global warming by reducing $\mathrm{CO}_{2}$ emissions) or the negative consequences for the quality of groundwater (stating the risk of acidification should $\mathrm{CO}_{2}$ leak from the storage reservoir) without mentioning any opposing information. The two-sided articles addressed both the advantage and disadvantage but emphasis was placed on one of them (cf. Druckman, 2001). The balanced article gave equal weight to advantages and disadvantages. See Appendix for an exact description of all five articles.

\section{Measures}

Relevance of arguments. To assess whether or not the advantage and the disadvantage mentioned in the articles related to environmental topics that participants considered relevant prior to reading the article, we asked: "To what extent do you find it 
important to combat global warming?" and "To what extent is quality of the groundwater important to you?" (1 = not at all, 7 = very much).

Perceived emphasis. We measured perceived emphasis (i.e., the manipulation check) within the article with two items: "To what extent did you feel that the emphasis in the article was on the advantages of CCS?" and "To what extent did you feel that the emphasis in the article was on the disadvantages of CCS?" ( 1 = not at all; $7=$ very $m u c h)$.

Perceived manipulation. We measured perceived manipulation with four items: "To what extent did you think that information was kept from you?," "To what extent did you think that you heard only one side of the story?," "To what extent did you perceive the information to be biased?", and "To what extent did you perceive the article as partial?" ( $1=$ not at all, $7=$ very much $), \alpha=.82$. The responses to these items were averaged into a single index of perceived manipulation.

Attitude toward CCS. We assessed participants' attitude toward CCS with four 9-point semantic differential scales (e.g., Petty \& Cacioppo, 1984): "I find CCS [badgood, harmful-beneficial, foolish-wise, unfavorable-favorable],” $\alpha=.91$.

\section{Results}

Relevance of arguments. Participants considered both environmental topics relevant. Ratings of relevance of ground water quality were significantly higher than the midpoint of the 7-point scale, $t(118)=22.27, p<.001(M=6.09, S D=1.03)$. Ratings of the relevance of combating global warming showed a similar effect, $t(118)=9.13$, $p<.001(M=5.18, S D=1.41) .^{3}$

Perceived emphasis. We performed a repeated measures analysis of variance (ANOVA) with Perceived Emphasis (Advantages vs. Disadvantages) as the withinsubjects factor and the five communication conditions as the between-subjects factor to check the adequacy of the communication manipulation. The results showed the anticipated Communication $\times$ Perceived Emphasis interaction, $F(4,115)=48.23$, $p<.001, \eta_{\mathrm{p}}^{2}=.63$. As intended, participants in the pro CCS conditions (one-sided and two-sided) perceived more emphasis on advantages than on disadvantages ( $p$ s < .001). By contrast, participants in the con CCS conditions (one-sided and twosided) perceived more emphasis on disadvantages than on advantages ( $p s \leq .001$ ). Interestingly, participants in the balanced condition also perceived more emphasis on advantages than on disadvantages $(p<.001)$. See Table 1 for means and standard deviations. 
Table 1. Means (and standard deviations) for perceived emphasis on advantages and disadvantages as a function of communication.

\begin{tabular}{lccccc}
\hline & $\begin{array}{c}\text { One-sided } \\
\text { pro CCS } \\
(N=24)\end{array}$ & $\begin{array}{c}\text { Two-sided } \\
\text { pro CCS } \\
(N=24)\end{array}$ & $\begin{array}{c}\text { Balanced } \\
(N=24)\end{array}$ & $\begin{array}{c}\text { Two-sided } \\
\text { con CCS } \\
(N=24)\end{array}$ & $\begin{array}{c}\text { One-sided } \\
\text { con CCS } \\
(N=24)\end{array}$ \\
\hline $\begin{array}{l}\text { Perceived emphasis on } \\
\text { advantages }\end{array}$ & $6.29(0.69)$ & $5.50(1.25)$ & $4.25(1.68)$ & $3.71(1.17)$ & $2.96(1.49)$ \\
$\begin{array}{l}\text { Perceived emphasis on } \\
\text { disadvantages }\end{array}$ & $1.71(1.30)$ & $3.00(1.02)$ & $2.71(0.96)$ & $4.92(1.35)$ & $5.04(1.65)$ \\
\hline
\end{tabular}

Perceived manipulation. We predicted that the use of emphasis framing would evoke higher levels of perceived manipulation compared to the provision of balanced information (Hypothesis 1). An ANOVA with communication as the independent variable and perceived manipulation as the dependent variable revealed a significant effect, $F(4,115)=5.44, p<.001, \eta_{\mathrm{p}}^{2}=.16$. Bonferroni post hoc analyses confirmed that participants perceived the article as significantly more manipulative when emphasis framing was applied (i.e., the one-sided and two-sided pro and con conditions) than when the article was balanced ( $p \leq \leq .01)$. The level of perceived manipulation did not differ between the four emphasis-frame conditions ( $p s=1.00$ ). See Table 2 for means and standard deviations.

Attitude toward CCS. We performed an ANOVA with communication as the independent variable and attitude toward CCS as the dependent variable to examine the extent to which emphasis framing influenced attitude. The analysis revealed a significant effect, $F(4,115)=3.15, p=.02, \eta_{\mathrm{p}}^{2}=.10$. Bonferroni post hoc analyses showed that people in the one-sided pro condition had a more positive attitude toward CCS $(M=6.25, S D=1.60)$ than people in the two-sided con condition $(M=4.55, S D=1.88), p=.02$. Further differences between conditions were not significant $(p s \geq .13)$. See Table 2 for means and standard deviations.

Table 2. Means (and standard deviations) for perceived manipulation and attitude toward CCS as a function of communication.

\begin{tabular}{lccccc}
\hline & $\begin{array}{c}\text { One-sided } \\
\text { pro CCS }\end{array}$ & $\begin{array}{c}\text { Two-sided } \\
\text { pro CCS }\end{array}$ & Balanced & $\begin{array}{c}\text { Two-sided } \\
\text { con CCS }\end{array}$ & $\begin{array}{c}\text { One-sided } \\
\text { con CCS }\end{array}$ \\
\hline $\begin{array}{l}\text { Perceived } \\
\text { manipulation }\end{array}$ & $5.15(1.00)$ & $5.10(1.42)$ & $3.83(1.26)$ & $4.94(0.88)$ & $4.93(1.06)$ \\
$\begin{array}{c}\text { Attitude } \\
\text { toward CCS }\end{array}$ & $6.25(1.60)$ & $5.57(1.89)$ & $5.57(1.80)$ & $4.55(1.88)$ & $4.94(1.84)$ \\
\hline
\end{tabular}

Note: Attitude toward CCS was measured on a 9-point scale. Perceived manipulation was measured on a 7-point scale. 


\section{Discussion}

Experiment 1 revealed the hypothesized effect of emphasis framing on perceived manipulation (Hypothesis 1). Participants perceived the biased news articles about CCS as more manipulative than the balanced article. Furthermore, Experiment 1 replicated-to some extent-findings from previous research that emphasis framing can affect attitudes. Participants who read that CCS can help combat global warming (without reading about risks for the quality of the ground water) were more positive toward the technology than participants who read that, although CCS can have both positive and negative consequences, the possible risks for the ground water outweigh the advantages for the climate.

Participants in the balanced condition perceived more emphasis on advantages than on disadvantages and evaluated CCS relatively positively. This effect was unanticipated (the effects of two competing frames with equal weight are expected to cancel out each other; Druckman, Peterson, \& Slothuus, 2013), but it did not interact with the predicted effects on perceived manipulation. As predicted, the balanced article was perceived as significantly less manipulative than the biased articles. A primacy effect might explain the unanticipated finding that participants in the balanced condition perceived more emphasis on advantages than on disadvantages and evaluated CCS as relatively positive. That is, in the balanced article, the advantage was mentioned before the disadvantage and information that is mentioned first can make more impression, can be better remembered, and can have more influence than information that follows (i.e., primacy effect; Asch, 1952; Crowley \& Hoyer, 1994). We did not make any hypotheses about a primacy effect beforehand, but we explore this possibility in Experiment 2.

\section{Experiment 2}

As explained earlier, Experiment 2 examines the combined effects of emphasis framing and communication source (i.e., news agency vs. oil company) on perceived manipulation and legitimacy judgments. The basic assumption underlying our predictions is that, in general, news agencies are expected to be less manipulative than oil companies. To check whether or not this assumption is correct, we assess expectations of manipulation prior to the presentation of the stimulus materials in Experiment 2. Furthermore, Experiment 2 includes two versions of the balanced article to counterbalance the order in which the advantage and disadvantage of CCS are presented. Counterbalancing allows us to check whether a primacy effect could be a viable explanation for the unexpected finding of Experiment 1 that participants in the balanced condition perceived more emphasis on advantages than on disadvantages.

Whereas Experiment 1 revealed that pro and con articles were considered equally manipulative, we selected the (two-sided) pro CCS article for use in Experiment 2. We chose this particular article in order to secure credibility. After all, it is more likely that an oil company that is involved in CCS emphasizes the benefits associated with the technology rather than the risks. 


\section{Method}

Participants and design. Participants were 139 undergraduate students from the Faculty of Social and Behavioral Sciences at Leiden University (32 male, 106 female [ 1 unspecified], $M_{\text {age }}=20.05, S D=2.82$ ). Eighty-one participants had heard about CCS prior to participation, 58 participants had not. Again, awareness of CCS did not moderate the results reported here and will not be discussed any further. Participants were randomly allocated to one of the six experimental conditions in this 2 (Source: news agency vs. oil company) $\times 3$ (Communication: two-sided pro CCS vs. balanced advantage-first vs. balanced disadvantage-first) between-subjects design. Participants received either $€ 1$ or course credits for their voluntary participation. Individuals who had participated in Experiment 1 were not allowed to participate in Experiment 2.

Procedure. The procedure was largely similar to that of Experiment 1, but the stimulus materials were presented as website articles instead of newspaper copies. Depending on experimental condition, the participants were informed that the article was either retrieved from the website of an independent news agency (the same source as in Experiment 1) or from the website of an unspecified oil company that invests in CCS. Regardless of the experimental condition, the articles were formatted equally without the display of logos, names, or affiliations. Participants in the pro CCS emphasis condition read the same content as participants in the pro CCS emphasis condition in Experiment 1. Participants in the balanced advantage-first condition read the same content as participants in the balanced condition in Experiment 1. Participants in the balanced disadvantage-first condition read a similar article, but here the disadvantage preceded the advantage. Upon completion of the experiment, participants were debriefed, paid, and thanked for their participation.

Measures. We used the same items as in Experiment 1 to measure perceived relevance of the arguments, perceived emphasis within the article, and perceived manipulation $(\alpha=.86)$.

Expected manipulation. We assessed the extent to which participants expected manipulation from news agencies and oil companies by means of five questions per source, asked prior to presentation of the article. The items read: "To what extent do you think that [news agencies/oil companies] try to influence the public opinion?," "To what extent do you think that [news agencies/oil companies] try to manipulate people by means of communication?," "To what extent do you think that [news agencies/oil companies] try to convince people of their own viewpoints?," "To what extent do you think that information from [news agencies/oil companies] is objective?," and "To what extent do you think that information from [news agencies/oil companies] is honest?" ( $1=$ not at all, $7=$ very much). The responses to these items were averaged into a single index of expected manipulation from oil companies $(\alpha=.89)$ and expected manipulation from news agencies $(\alpha=.89)$. 
Legitimacy judgments. Participants' judgments of the legitimacy of the article were assessed by means of four 9-point semantic differential scales. Participants were requested to respond to the phrase "I consider the manner in which the article describes the issue of CCS [illegitimate-legitimate, unacceptable-acceptable, inappropriate-appropriate, not suitable-suitable]," $\alpha=.93$. Responses were averaged to form a single index of legitimacy judgments.

Principal component analysis with Varimax rotation revealed that legitimacy judgments and perceived manipulation represented different constructs. The items loaded on two separate components with no substantial cross loadings (all cross loadings $\leq-.18$ ) explaining a total variance of $76.22 \%$ in the individual items. The eigenvalue of the first component (legitimacy judgments) was 4.93; the eigenvalue of the second component (perceived manipulation) was 1.17 .

\section{Results}

Relevance of arguments. As in Experiment 1, participants considered both environmental topics relevant. Ratings of relevance of ground water quality were significantly higher than the midpoint of the 7-point scale $(t[137]=18.30, p<.001[M=5.78, S D$ $=1.14])$, as were ratings of the relevance of combating global warming, $(t[137]=$ 14.19, $p<.001[M=5.31, S D=1.09]){ }^{4}$

Expected manipulation. As anticipated, participants expected news agencies to be significantly less manipulative $(M=4.25, S D=1.12)$ than oil companies $(M=5.06$, $S D=1.11), t(138)=-5.83, p<.001$. This validated our manipulation of source identity.

Perceived emphasis. A repeated measures ANOVA with Perceived Emphasis as the within-subjects factor and Communication as the between-subject factors showed a significant interaction-effect, $F(2,136)=17.29, p<.001, \eta_{\mathrm{p}}^{2}=.20$. As in Experiment 1 , participants in the pro CCS and balanced conditions perceived more emphasis on advantages in the article than on disadvantages. However, this perceived imbalance was clearest in the pro CCS condition. More specifically, within this condition, we found the largest difference between perceived emphasis on advantages $(M=5.67$, $S D=1.21)$ vs. disadvantages $(M=2.74, S D=1.20), F(1,45)=85.39, p<.001, \eta_{\mathrm{p}}^{2}=.66$. Participants in the two balanced conditions also perceived more emphasis on advantages than on disadvantages. However, these differences were less pronounced than in the pro CCS condition. Importantly, the difference did not only occur in the balanced advantage-first condition $\left(M_{\text {advantages }}=4.51, S D=1.52, M_{\text {disadvantages }}=3.26\right.$, $\left.S D=1.21, F[1,46]=27.71, p<.001, \eta_{\mathrm{p}}^{2}=.38\right)$, but also in the balanced disadvantagefirst condition $\left(M_{\text {advantages }}=3.80, S D=1.54, M_{\text {disadvantages }}=3.17, S D=1.32, F[1,45]=4.50\right.$, $\left.p=.039, \eta_{\mathrm{p}}^{2}=.09\right)$. Thus, the order in which the arguments were provided cannot explain the perceived emphasis on advantages over disadvantages. Therefore, we do not differentiate 
between the two balanced conditions in all further analyses, but focus on the pro CCS article vs. balanced article contrast instead.

Perceived manipulation. To test Hypotheses 1 and 2, we performed an ANOVA with the communication contrast (pro CCS condition vs. the two balanced conditions) and source as the independent variables, and perceived manipulation as the dependent variable. In support of Hypothesis 1, this analysis revealed a significant main effect of the communication contrast, $F(1,133)=25.58, p<.001, \eta_{\mathrm{p}}^{2}=.16$. Participants in the pro CCS condition perceived the article as more manipulative $(M=4.76, S D=1.36)$ than participants in the balanced conditions $\left(M_{\text {adv-first }}=3.91, S D=1.33, M_{\text {disadv-first }}=\right.$ 3.32, $S D=1.21$ ). Furthermore, we found the predicted main effect of source (Hypothesis 2). Participants perceived the article as more manipulative when it was produced by an oil company $(M=4.31, S D=1.32)$ than when it was produced by a news agency $(M=3.68, S D=1.46), F(1,133)=8.63, p=.004, \eta_{\mathrm{p}}^{2}=.06$. There was no interaction effect, $F(1,133)=0.99, p=.32$, indicating that the effect of the type of communication (biased vs. balanced) on perceived manipulation was not moderated by the identity of the source. See Table 3 for all means and standard deviations.

Legitimacy judgments. We predicted that for news agencies, providing biased information is considered as less legitimate than providing balanced information, but for oil companies, this does not hold true (Hypothesis 3). To test this prediction, we performed an ANOVA with the communication contrast and source as the independent variables, and legitimacy judgments as the dependent variable. The analysis revealed a main effect of the communication contrast, $F(1,133)=13.26$, $p<.001, \eta_{\mathrm{p}}^{2}=.09$, a main effect of source, $F(1,133)=4.19, p=.043, \eta_{\mathrm{p}}^{2}=.03$, and the

Table 3. Means (and standard deviations) for perceived manipulation, legitimacy judgments, and attitude toward CCS as a function of source and communication.

\begin{tabular}{lcccccccc}
\hline & \multicolumn{3}{c}{ News agency } & & \multicolumn{3}{c}{ Oil company } \\
\cline { 2 - 3 } & $\begin{array}{c}\text { Two-sided } \\
\text { pro CCS } \\
(N=23)\end{array}$ & $\begin{array}{c}\text { Balanced } \\
\text { (adv. first }) \\
(N=23)\end{array}$ & $\begin{array}{c}\text { Balanced } \\
\text { (disadv. } \\
\text { first) } \\
(N=23)\end{array}$ & $\begin{array}{c}\text { Two-sided } \\
\text { pro CCS } \\
(N=23)\end{array}$ & $\begin{array}{c}\text { Balanced } \\
\text { (adv. first) } \\
(N=24)\end{array}$ & $\begin{array}{c}\text { Balanced } \\
\text { (disadv. } \\
\text { first) } \\
(N=23)\end{array}$ \\
\hline $\begin{array}{c}\text { Perceived } \\
\text { manipulation }\end{array}$ & $4.60(1.52)$ & $3.75(1.23)$ & $2.71(0.94)$ & $4.92(1.18)$ & $4.07(1.43)$ & $3.93(1.14)$ \\
$\begin{array}{c}\text { Legitimacy } \\
\text { judgments }\end{array}$ & $5.50(1.31)$ & $6.43(1.02)$ & $7.21(1.07)$ & $5.70(1.33)$ & $6.18(1.40)$ & $5.93(1.48)$ \\
$\begin{array}{c}\text { Attitude } \\
\text { toward CCS }\end{array}$ & $5.10(1.80)$ & $5.71(1.45)$ & $5.51(1.49)$ & $5.50(1.39)$ & $5.47(1.34)$ & $5.33(1.79)$ \\
\hline
\end{tabular}

Note: Attitude toward CCS and legitimacy judgments were measured on 9-point scales. Perceived manipulation was measured on a 7-point scale. The effect of pro CCS communication on attitude could not be compared with the effect of communication against CCS because the design did not include a con condition. However, in order to be consistent, we assessed participants' attitude toward CCS with the same semantic differential scales as in Experiment $1, \alpha=.86$. An ANOVA with the communication contrast and source as the independent variables, and attitude toward CCS as the dependent variable revealed no statistically significant effects ( $p s \geq .26)$. 
hypothesized interaction effect, $F(1,133)=4.33, p=.039, \eta_{\mathrm{p}}^{2}=.03$. Participants in the news agency condition judged the biased article as less legitimate than the balanced articles, whereas such a difference was not observed in the oil company condition. These results offer support for Hypothesis 3. See Table 3 for all means and standard deviations.

Furthermore, we predicted that the relation between perceived manipulation and legitimacy judgments is stronger when people evaluate communications from news agencies than when they evaluate communications from oil companies (Hypothesis 4). Consistent with this hypothesis, we found that the more manipulative a news agency's article was perceived, the less legitimate it was considered to be $(r=-.74$, $p<.001)$. This correlation was less strong when the article came from an oil company $(r=-.47, p<.001)$. Fisher's $Z$ test confirmed that the difference between these correlation coefficients was significant, $z=-2.54, p=.011$.

Mediation. Furthermore, we performed a bootstrap analysis that allows for the inclusion of contrast coding (Hayes \& Preacher, 2014) to test whether the effect of emphasis framing on legitimacy judgments in the news agency condition was mediated by perceived manipulation. This approach uses resampling of raw data to estimate the confidence interval (CI) of the indirect effect. We used 10,000 resamples (bias corrected) and obtained a 95\% CI that did not include zero (lower CI $=0.36$; upper $\mathrm{CI}=1.41$ ), indicating the proposed indirect effect.

\section{General Discussion}

The implementation of CCS technology is considered a useful measure to achieve significant $\mathrm{CO}_{2}$ emission reductions in the short run. In the current experimental research, we examined how participants responded to communications about CCS with various degrees of imbalance in the reporting of advantages and disadvantages of this technology (i.e., emphasis framing). Specifically, we investigated how emphasis framing affects attitudes toward CCS, as well as perceptions of manipulation and judgments of legitimacy concerning the use of this persuasive communication technique.

Our research contributes to existing literature by revealing potential pitfalls in the use of emphasis framing. We discovered that emphasis framing can be perceived as manipulative, which is particularly problematic when impartiality is expected. We addressed emphasis framing by the provision of articles that either emphasized an advantage of CCS (i.e., combating global warming) or a disadvantage (i.e., the risk of groundwater acidification). We found that no matter what direction participants were pushed into or how hard they were being pushed, they perceived a biased article as more manipulative than a balanced article. That is, regardless of whether the article reported only on the positive or negative consequences of CCS (one-sided framing), or covered both aspects but placed emphasis on one of them (two-sided framing), the article was perceived as more manipulative than an article that gave equal weight to advantages and disadvantages. 
When news agencies emphasized the advantages of CCS in their coverage, participants in our studies found this manipulation inappropriate. When oil companies emphasized these advantages, participants also found it manipulative (even more than when this was done by news agencies), but in this case it did not result in judgments of illegitimacy. We demonstrated that this difference was caused by expectations; oil companies were more associated with persuasive communication techniques than news agencies. This finding is in line with general views that news agencies are expected to be balanced (Ryan, 2001) and commercial organizations to be biased (e.g., Campbell, 1995). Thus, expectations can play a large role in whether emphasis framing is considered as illegitimate or not.

Finally, the current research indicates that emphasis framing can be an effective communication technique when it comes to influencing attitudes toward CCS. Participants in our studies had a more positive attitude toward CCS after reading a positively framed article about the technology than after reading a negatively framed article. This finding in the domain of energy technologies adds to previous research on the effectiveness of emphasis framing on the shaping of attitudes (Druckman \& Bolsen, 2011; Nelson et al., 1997).

\section{Limitations and future research}

One might expect that if advantages and disadvantages of an issue receive equal weight in a news article, they would cancel out each other's effect on attitude (Druckman et al., 2013). However, participants in our studies were relatively positive about CCS (and perceived more emphasis on advantages) after reading an article with equal emphasis on the technology's advantage and disadvantage. This finding is especially interesting because participants expressed relatively more concern for the disadvantage (i.e., the risk of groundwater acidification) than for the advantage (i.e., combating global warming). We ruled out that this effect was due to the order in which the advantage and the disadvantage were presented. A possible explanation is that participants perceived general information about CCS, provided in the opening paragraph of the article, as positive. Although we strived to provide a neutral introduction, it portrayed CCS as a way to meet targets set in international agreements to reduce $\mathrm{CO}_{2}$ emissions, which could be regarded as an advantage. Importantly, despite this perceived emphasis on advantages over disadvantages, participants evaluated the balanced article as significantly less manipulative than the biased articles. Thus, although the factual description of CCS may not have been perceived as completely neutral, this perception has no implications for the impact of our experimental manipulations, nor does it undermine the interpretation of our results and the validity of our conclusions.

At the same time, we realize that our results and conclusions are based on samples of undergraduate students in social and behavioral studies with an overrepresentation of females. Even though we cannot immediately think of clear reasons why the current findings would not apply to the public as a whole, we do acknowledge that they not necessarily generalize to other subpopulations. For instance, different 
psychological processes might come into play when people live near a proposed CCS demonstration site and are thus personally confronted with CCS. Greater personal involvement with an issue typically makes people process information more systematically (Chaiken, 1980; Petty \& Cacioppo, 1986), which can limit the power of framing (Brewer, 2001; Joslyn \& Haider-Markel, 2002). Furthermore, local residents are more likely to have negative opinions about CCS if they believe that it is unsafe to transport and store $\mathrm{CO}_{2}$, or if they fear falls in local property value (Terwel et al., 2012). In that case, they might focus primarily on arguments against the implementation of CCS (i.e., selective exposure; Frey, 1986; Hart et al., 2009; Smith, Fabrigar, \& Norris, 2008) and dismiss any pro-CCS arguments as manipulative. As a result, it is unlikely that a positively framed message will be sufficient to change existing, already strongly negative attitudes. Future research could take a closer look at how issue involvement influences the extent to which people consider communications as manipulative or (il)legitimate.

Another factor that might interact with the impact of framing when communicating about CCS is the extent to which people value equality, authority, individualism, and community. These cultural values influence risk perceptions and related beliefs (cultural cognition; Douglas \& Wildavsky, 1982) and are suggested to explain disagreements in environmental-risk perceptions more completely than any other individual characteristic (Kahan, 2010). People that subscribe to relatively individualistic and hierarchical values tend to value commerce and industry, and resist scientific evidence that climate change is a serious threat. They assume that industry-constraining carbon-emission limits are the main solution for global warming (Kahan, 2010). Therefore, individualists might have a positive attitude toward CCS. Probably, they have a more positive attitude toward CCS than people who subscribe to more egalitarian and communitarian values. That is, people with egalitarian outlooks tend to belief claims of environmental risks and distrust commerce and industry (Kahan, 2010). It is likely that egalitarians perceive CCS as a measure that enables industries to continue using fossil fuel energy sources and hampers the development of renewable energy sources.

Because egalitarians distrust industry, they probably perceive all CCS-related information from oil companies as manipulative and unacceptable. As such, the positive impact of a balanced CCS message from an oil company is likely dampened amongst this group. In comparison with egalitarians, individualists probably perceive CCS messages from oil companies as less manipulative, because individualists appreciate industry. Presumably, the positive impact of a balanced CCS message from an oil company is amplified among this group. In contrast, it is likely that individualists-more than egalitarians-perceive a biased CCS message from an environmental NGO (e.g., to convince people to oppose implementation) as very manipulative. Future research may examine these possible moderating effects of cultural cognition.

Implications. We know from prior research that communications about environmental issues are most effective when they fit people's expectations about their 
purposes (Rabinovich et al., 2012). This would imply that the best strategy for oil companies would be to communicate about CCS in a persuasive manner. Indeed, the current research seems to suggest that oil companies can apply emphasis framing relatively hassle-free. However, it might sometimes be better for oil companies to provide balanced instead of biased information, depending on their goal. An oil company that only pursues the short-term goal of convincing people to support the implementation of CCS can probably best provide information with an emphasis on the benefits of the technology. Namely, in line with previous research, our findings indicate that emphasis framing can be effective when it comes to influencing people's attitudes. However, it should be noted that framing might not be very effective when the source has low credibility (Druckman, 2001) and oil companies are generally not considered as very credible when it comes to communicating about environmental issues (Terwel et al., 2009a).

When an oil company does not want to harm its corporate image, it could better provide balanced information about CCS. The current research indicates that balanced messages are perceived as less manipulative than biased messages, and although we also found that manipulation is not necessarily judged as inappropriate for stakeholders with an interest in CCS, manipulation is associated with negative image effects in the long run (see Campbell, 1995). British Petroleum (BP) provides an illustration of the potential harmful effects of perceived manipulation on the image of an oil company. When BP framed its corporate activities in a publicity campaign in terms of commitment to the environment, while investing mainly in polluting fossil fuels instead of renewables, their intentions were challenged (García, 2011; Le Menestrel, van den Hove, \& De Bettignies, 2002) and Greenpeace publicly accused BP of "greenwashing” ("BP wins coveted 'Emerald Paintbrush' award”, 2008). Corporate greenwashing is perceived when a company seems to misrepresent its activities as "green" in order to look more environmentally friendly than it actually is (e.g., Laufer, 2003; Vos, 2009) and is linked to several long-term unwanted effects including consumer protest and boycott, and financial loss for the company (e.g., Polonsky, 1995; Polonsky \& Rosenberger III, 2001). Experimental research shows support for this negative framing effect in the domain of CCS. Oil companies that frame their investment in the development of CCS in environmental terms instead of economic terms are suspected of strategic behavior and accused of greenwashing (de Vries, Terwel, Ellemers, \& Daamen, 2015). In short, although sharing unbiased (i.e., nonmanipulative) information might not be the first-choice strategy for oil companies with a clear interest in achieving implementation of CCS, it might be their best choice if they do not want to harm their image. Moreover, providing balanced information about CCS might even lead to positive long-term effects such as increased trust in their integrity (cf. Terwel, Harinck, Ellemers, \& Daamen, 2009b).

Our findings seem to imply that news agencies best cover CCS in a balanced manner. Journalistic balance is particularly relevant when covering controversial issues that involve competing viewpoints, such as CCS. However, in their effort to give equal room to opposing views, journalists covering CCS should beware of 
providing "false balance." That is, they should be careful not to present a view supported by an overwhelming amount of evidence alongside a view with less support while suggesting that both views are equally strong (Dearing, 1995). False balance in news articles can result in heightened uncertainty among the public and belief that experts are divided on the issue (Dixon \& Clarke, 2013). It is speculated that the debate on global warming and the implementation of $\mathrm{CO}_{2}$ emission reduction measures has been attenuated because of equal journalistic emphasis on humaninduced warming (a view backed up by a scientific consensus) and nature-induced warming (a view that has less scientific support) (Boykoff \& Boykoff, 2004). In sum, news agencies best cover both advantages and disadvantages of CCS but should be clear about where the strength of evidence lies.

The question remains how people perceive the use of emphasis framing in communications from other sources than news agencies or oil companies, such as national and local government, (environmental) non-governmental organizations, pressure groups, and scientists. For instance, do people perceive a geophysicist as manipulative when she provides a predominantly positive message about CCS? Our findings suggest that perceived legitimacy and manipulative intentions may be predicted depending on expectations about the overall aims and goals of the communicating parties with regard to CCS. In other words, people probably perceive a geophysicist who is fully paid by industrial partners with a large interest in CCS as more manipulative than a geophysicist who is paid by a university with no ties with CCS projects.

Because CCS is a controversial technology, the public debate is strong and clusters around several topics such as whether the technology genuinely helps to solve global warming or reaffirms our ability to continue to use fossil fuel energy sources (and grow the economy) while hampering the development of renewable energy sources (e.g., van Egmond \& Hekkert, 2012). Similar debates have accompanied the introduction of other energy sources like biofuel (Wright \& Reid, 2011) and nuclear power (Arentsen, 2006). The implication of the current research for these public debates is that people can approach messages about these issues in a more critical manner when they learn about the processes that are instigated by persuasive communication techniques. Forewarning people of the existence of persuasive tactics can help them resist persuasion (see Benoit, 1998), especially if their illusions of invulnerability to persuasion are dispelled (e.g., Sagarin, Cialdini, Rice, \& Serna, 2002). As more critical consumers, people can more effectively use information to derive an informed opinion about difficult issues such as CCS and participate in the public debate properly resourced.

\section{Acknowledgments}

This research has been carried out in the context of the CATO-2-program. CATO-2 is the Dutch national research program on CCS technology. We acknowledge the useful comments and suggestions of Dancker Daamen, who passed away on 27 September 2012. 


\section{Disclosure statement}

No potential conflict of interest was reported by the authors.

\section{Funding}

The program is financially supported by the Dutch Government (Ministry of Economic Affairs) and the CATO-2 consortium parties.

\section{Supplemental Data}

Supplemental data for this article can be accessed at http://dx.doi.org/10.1080/17524032.2015. 1047884 .

\section{Notes}

1. Another well-known type of framing is "equivalency framing." This type of framing refers to ways in which logically equivalent alternative phrases (e.g., " $75 \%$ fat free" vs. " $25 \%$ fat") can lead to different attitudes and/or decisions (e.g., Levin, Schneider, \& Gaeth, 1998; Tversky \& Kahneman, 1981). Equivalency framing will not be studied in the current research.

2. We do not report all measures in this paper for reasons of clarity and conciseness. Measures and results are available on request.

3. One person did not answer these questions.

4. One person did not answer these questions.

\section{References}

Arentsen, M. (2006). Contested technology: Nuclear power in the Netherlands. Energy \& Environment, 17, 373-382. doi:10.1260/095830506778119407

Asayama, S., \& Ishii, A. (2013). Exploring media representation of carbon capture and storage: An analysis of Japanese newspaper coverage in 1990-2010. Energy Procedia, 37, 7403-7409.

Asch, S. E. (1952). Social psychology. Englewood Cliffs. NJ: Prentice Hall.

Benoit, W. L. (1998). Forewarning and persuasion. In M. Allen \& R. Preiss (Eds.), Persuasion: Advances through meta-analysis (pp. 139-154). Creskill, NJ: Hampton Press.

Boykoff, M., \& Boykoff, J. (2004). Balance as bias: Global warming and the U.S. prestige press. Global Environmental Change, 15, 125-136. doi:10.1016/j.gloenvcha.2003.10.001

BP wins coveted 'Emerald Paintbrush' award for worst greenwash of 2008. (2008). Retrieved November 9, 2011, from http://www.greenpeace.org.uk/blog/climate/bps-wins-coveted-emer ald-paintbrush-award-worst-greenwash-2008-20081218/

Brewer, P. R. (2001). Value words and lizard brains. Political Psychology, 22, 45-64. doi:10.1111/ 0162-895X.00225

Brunsting, S., de Best-Waldhober, M., Feenstra, C. F. J., \& Mikunda, T. (2011). Stakeholder participation practices and onshore CCS: Lessons from the Dutch CCS case Barendrecht. Energy Procedia, 4, 6376-6383. doi:10.1016/j.egypro.2011.02.655

Campbell, M. C. (1995). When attention-getting advertising tactics elicit consumer inferences of manipulative intent: The importance of balancing benefit and investments. Journal of Consumer Psychology, 4, 225-254. doi:10.1207/s15327663jcp0403_02

Campbell, M. C., \& Kirmani, A. (2000). Consumers' use of persuasion knowledge: The effects of accessibility and cognitive capacity on perceptions of an influence agent. Journal of Consumer Research, 27, 69-83. doi:10.1086/314309 
Chaiken, S. (1980). Heuristic versus systematic information processing and the use of source versus message cues in persuasion. Journal of Personality and Social Psychology, 39, 752-766. doi:10.1037/0022-3514.39.5.752

Chong, D., \& Druckman, J. N. (2007). Framing theory. Annual Review of Political Science, 10, 103-126. doi:10.1146/annurev.polisci.10.072805.103054

Cobb, M. D. (2005). Framing effects on public opinion about nanotechnology. Science Communication, 27, 221-239. doi:10.1177/1075547005281473

Crowley, A. E., \& Hoyer, W. D. (1994). An integrative framework for understanding two-sided persuasion. Journal of Consumer Research, 20, 561-574. doi:10.1086/209370

Dearing, J. W. (1995). Newspaper coverage of maverick science: Creating controversy through balancing. Public Understanding of Science, 4, 341-361. doi:10.1088/0963-6625/4/4/002

de Vries, G., Terwel, B. W., Ellemers, N., \& Daamen, D. D. L. (2015). Sustainability or profitability? How communicated motives for environmental policy affect public perceptions of corporate greenwashing. Corporate Social Responsibility and Environmental Management, 22, 142-154. doi:10.1002/csr.1327

Dixon, G. N., \& Clarke, C. E. (2013). Heightening uncertainty around certain science media coverage, false balance, and the autism-vaccine controversy. Science Communication, 35, 358-382. doi:10.1177/1075547012458290

Douglas, M., \& Wildavsky, A. B. (1982). Risk and culture: An essay on the selection of technical and environmental dangers. Berkeley: University of California Press.

Druckman, J. N. (2001). On the limits of framing effects: Who can frame? The Journal of Politics, 63, 1041-1066. doi:10.1111/0022-3816.00100

Druckman, J. N., \& Bolsen, T. (2011). Framing, motivated reasoning, and opinions about emergent technologies. Journal of Communication, 61, 659-688. doi:10.1111/j.1460-2466.2011.01562.x

Druckman, J. N., Peterson, E., \& Slothuus, R. (2013). How elite partisan polarization affects public opinion formation. American Political Science Review, 107, 57-79. doi:10.1017/S0003055 412000500

Feldpausch-Parker, A. M., Ragland, C. J., Melnick, L. L., Chaudhry, R., Hall, D. M., Peterson, T. R., ... Wilson, E. J. (2013). Spreading the news on carbon capture and storage: A state-level comparison of US media. Environmental Communication, 7, 336-354. doi:10.1080/17524032. 2013.807859

Fishbein, M., \& Ajzen, I. (1975). Belief, attitude, intention, and behavior: An introduction to theory and research. Reading, MA: Addison-Wesley.

Fiske, S. T., \& Taylor, S. E. (1991). Social cognition. New York, NY: McGraw-Hill.

Frey, D. (1986). Recent research on selective exposure to information. In L. Berkowitz (Ed.), Advances in experimental social psychology (pp. 41-80). New York, NY: Academic Press.

Friestad, M., \& Wright, P. (1994). The persuasion knowledge model: How people cope with persuasion attempts. Journal of Consumer Research, 21, 1-31. doi:10.1086/209380

García, M. M. (2011). Perception is truth: How U.S. newspapers framed the 'go green' conflict between BP and greenpeace. Public Relations Review, 37, 57-59. doi:10.1016/j.pubrev.2010.10.001

Gass, R. H., \& Seiter, J. S. (2007). Persuasion, social influence, and compliance gaining (3rd ed.). Boston, MA: Allyn and Bacon/Pearson.

Hart, W., Albarracín, D., Eagly, A. H., Brechan, I., Lindberg, M. J., \& Merrill, L. (2009). Feeling validated versus being correct: A meta-analysis of selective exposure to information. Psychological Bulletin, 135, 555-588. doi:10.1037/a0015701

Hayes, A. F., \& Preacher, K. J. (2014). Statistical mediation analysis with a multicategorical independent variable. British Journal of Mathematical and Statistical Psychology, 67, 451-470. doi:10.1111/bmsp.12028

Hovland, C. I., Janis, I. L., \& Kelley, H. H. (1953). Communication and persuasion: Psychological studies of opinion change. New Haven, CT: Yale University Press. 
IPCC. (2007). Summary for policymakers. In B. Metz, O. R. Davidson, P. R. Bosch, R. Dave, \& L. A. Meyer (Eds.), Climate change 2007: Mitigation. Contribution of working group III to the fourth assessment report of the Intergovernmental Panel on Climate Change (pp. 9-18). Cambridge and New York, NY: Cambridge University Press.

IPCC. (2013). Summary for policymakers. In T. F. Stocker, D. Qin, G.-K. Plattner, M. Tignor, S. K. Allen, J. Boschung, A. Nauels, Y. Xia, V. Bex, \& P. M. Midgley (Eds.), Climate change 2013: The physical science basis. Contribution of working group I to the fifth assessment report of the Intergovernmental Panel on Climate Change (pp. 2-13). Cambridge and New York, NY: Cambridge University Press.

Jones, C. R., Eiser, J. R., \& Gamble, T. R. (2012). Assessing the impact of framing on the comparative favourability of nuclear power as an electricity generating option in the UK. Energy Policy, 41, 451-465. doi:10.1016/j.enpol.2011.11.006

Joslyn, M. R., \& Haider-Markel, D. P. (2002). Framing effects on personal opinion and perceptions of public opinion: The cases of physician-assisted suicide and social security. Social Science Quarterly, 83, 690-706. doi:10.1111/1540-6237.00109

Kahan, D. (2010). Fixing the communications failure. Nature, 463, 296-297. doi:10.1038/463296a

Laufer, W. S. (2003). Social accountability and corporate greenwashing. Journal of Business Ethics, 43, 253-261. doi:10.1023/A:1022962719299

Le Menestrel, M., van den Hove, S., \& de Bettignies, H.-C. (2002). Processes and consequences in business ethical dilemmas: The oil industry and climate change. Journal of Business Ethics, 41, 251-266. doi:10.1023/A:1021237629938

Levin, I. P., Schneider, S. L., \& Gaeth, G. J. (1998). All frames are not created equal: A typology and critical analysis of framing effects. Organizational Behavior and Human Decision Processes, 76, 149-188. doi:10.1006/obhd.1998.2804

Lichtenberg, J. (2000). In defence of objectivity revisited. In J. Curran \& M. Gurevitch (Eds.), Mass media and society (pp. 238-254). London: Arnold.

Nelson, T. E., Clawson, R. A., \& Oxley, Z. M. (1997). Media framing of a civil liberties conflict and its effect on tolerance. The American Political Science Review, 91, 567-583. doi:10.1023/a: 1024834831093

Nerlich, B., \& Jaspal, R. (2013). UK media representations of carbon capture and storage: Actors, frames and metaphors. Metaphor and the Social World, 3(1), 35-53. doi:10.1075/msw.3.1.02ner

Nisbet, M. C. (2009). Communicating climate change: Why frames matter for public engagement. Environment: Science and Policy for Sustainable Development, 51, 12-23. doi:10.3200/ ENVT.51.2.12-23

Petty, R. E., \& Cacioppo, J. T. (1984). The effects of involvement on responses to argument quantity and quality: Central and peripheral routes to persuasion. Journal of Personality and Social Psychology, 46, 69-81. doi:10.1037/0022-3514.46.1.69

Petty, R. E., \& Cacioppo, J. T. (1986). The elaboration likelihood model of persuasion. In L. Berkowitz (Ed.), Advances in experimental social psychology (pp. 123-205). New York, NY: Academic Press.

Polonsky, M. J. (1995). Cleaning up environmental marketing claims: A practical checklist. In M. J. Polonsky \& A. T. Mintu-Wimsatt (Eds.), Environmental marketing (pp. 199-223). Binghamton, NY: Haworth.

Polonsky, M. J., \& Rosenberger III, P. J. (2001). Reevaluating green marketing: A strategic approach. Business Horizons, 44, 21-30. doi:10.1016/S0007-6813(01)80057-4

Rabinovich, A., Morton, T. A., \& Birney, M. E. (2012). Communicating climate science: The role of perceived communicator's motives. Journal of Environmental Psychology, 32, 11-18. doi:10.1016/j.jenvp.2011.09.002

Ryan, M. (2001). Journalistic ethics, objectivity, existential journalism, standpoint epistemology, and public journalism. Journal of Mass Media Ethics, 16, 3-22. doi:10.1207/S15327728JMME1601_2 
Sagarin, B. J., Cialdini, R. B., Rice, W. E., \& Serna, S. B. (2002). Dispelling the illusion of invulnerability: The motivations and mechanisms of resistance to persuasion. Journal of Personality and Social Psychology, 83, 526-541. doi:10.1037/0022-3514.83.3.526

Smith, S. M., Fabrigar, L. R., \& Norris, M. E. (2008). Reflecting on six decades of selective exposure research: Progress, challenges, and opportunities. Social and Personality Psychology Compass, 2, 464-493. doi:10.1111/j.1751-9004.2007.00060.x

Ter Mors, E., Weenig, M. W. H., Ellemers, N., \& Daamen, D. D. L. (2010). Effective communication about complex environmental issues: Perceived quality of information about carbon dioxide capture and storage (CCS) depends on stakeholder collaboration. Journal of Environmental Psychology, 30, 347-357. doi:10.1016/j.jenvp.2010.06.001

Terwel, B. W., Harinck, F., Ellemers, N., \& Daamen, D. D. L. (2009a). How organizational motives and communications affect public trust in organizations: The case of carbon dioxide capture and storage. Journal of Environmental Psychology, 29, 290-299. doi:10.1016/j.jenvp.2008.11.004

Terwel, B. W., Harinck, F., Ellemers, N., \& Daamen, D. D. L. (2009b). Competence-based and integrity-based trust as predictors of acceptance of carbon dioxide capture and storage (CCS). Risk Analysis, 29, 1129-1140. doi:10.1111/j.1539-6924.2009.01256.x

Terwel, B. W., Ter Mors, E., \& Daamen, D. D. L. (2012). It's not only about safety: Beliefs and attitudes of 811 local residents regarding a CCS project in Barendrecht. International Journal of Greenhouse Gas Control, 9, 41-51. doi:10.1016/j.ijggc.2012.02.017

Tversky, A., \& Kahneman, D. (1981). The framing of decisions and the psychology of choice. Science, 211, 453-458. doi:10.1126/science.7455683

UN. (1998). Kyoto protocol to the United Nations framework convention on Climate change. Retrieved from http://unfccc.int/resource/docs/convkp/kpeng.pdf

UN. (2012). Doha amendment to the Kyoto protocol. Retrieved from http://unfccc.int/files/ kyoto_protocol/application/pdf/kp_doha_amendment_english.pdf

Van Egmond, S., \& Hekkert, M. P. (2012). Argument map for carbon capture and storage. International Journal of Greenhouse Gas Control, 11, S148-S159. doi:10.1016/j.ijggc.2012.08.010

Vos, J. (2009). Actions speak louder than words: Greenwashing in corporate America. Notre Dame Journal of Law, Ethics \& Public Policy, 23, 673-697.

WMO. (2013). Greenhouse gas bulletin. The state of greenhouse gases in the atmosphere based on global observations through 2012. Retrieved from www.wmo.int

Wright, W., \& Reid, T. (2011). Green dreams or pipe dreams? Media framing of the U.S. biofuels movement. Biomass and Bioenergy, 35, 1390-1399. doi:10.1016/j.biombioe.2010.07.020 